\title{
The Impact of Using Instagram Social Media on Student Consumptive Behavior
}

\author{
Rully Khairul Anwar ${ }^{1}$, Ute Lies Siti Khadijah ${ }^{1}$, Diah Fatma \\ Sjoraida $^{1}$, M. Taufiq Rahman ${ }^{2}$ \\ ${ }^{1}$ University of Padjadjaran \\ ${ }^{2}$ Sunan Gunung Djati State Islamic University of Bandung
}

Paper Type:

Research Paper

\begin{abstract}
Background of the study: The online shop is a process of buying and selling transactions conducted by the public through the internet media. We don't have to leave the house, people can have the items they want through an online shop. The use of the internet by students cannot be separated, including using in consumption patterns through online shops. The existence of the development of telecommunications technology, online shop currently makes it easy for students to make transactions or market products, goods and services. They are not only consumers, but also online shop business people.
\end{abstract}

Purpose: This study aims to determine the impact of the use of Instagram on consumptive behavior of Islam-based students in Bandung.

Method: This qualitative research uses a descriptive method by taking a location on an Islamic-based campus in Bandung.

Findings: There is a rationalization behind the use of Instagram of female students, in addition it was also found that female students use Instagram mainly for the improvement and adjustment of lifestyle with trending topics, especially the style of the artist. For those who have more money, the students also make online transactions to buy clothes they like.

Conclusion: 1) Instagram is a phenomenal social media among female college students because users are spoiled with various features available on Instagram, 2) the campus provides a large bandwidth so they can access Instagram more easily, and 3) the impact of expanding access to the internet becomes they are more consumptive to do transactions face to face.

Keywords : stimulus-response theory, campus life, Instagram, social media
Submitted: 30 July 2019 Accepted: 11 April 2020

* Correspondence: Rully Khairul Anwar

E-mail: rully.khairul@unpad.ac.id 


\section{Introduction}

Globalization is a change that has a good effect on the development of life. The existence of globalization makes various development progress very rapidly, especially in the sector of technology and information. The many advances in communication technology prove this so that the changes occur thoroughly, felt collective, and affect many people until it influences the lifestyle and our surroundings. But globalization also has complicated consequences for every country, especially developing countries such as Indonesia, globalization causes the world to be unlimited, and the main cause of globalization today is the advancement of information and communication technology (Indermun, 2014).

The Internet is a network of interconnected computer networks using the Global Transmission Control Protocol / Internet Protocol Suite (TCP / IP) system as a packet-switching communication protocol to serve billions of users worldwide. The Internet can be defined as a large worldwide computer network connecting computer users from one country to another throughout the world, where various information resources are ranging from static to dynamic and interactive (Gubbi, Buyyab, Marusica, \& Palaniswamia, 2013).

The Internet is a communication system capable of connecting computer networks around the world. With the Internet, a computer will be able to connect with other computers anywhere, as long as it has internet facilities. Also, the internet also provides a variety of facilities that allow users to access a variety of desired information. Moreover, now there are many sophisticated communication technologies such as smartphones with various brands such as Samsung, Asus, Nokia, Xiaomi, Oppo, Lenovo and others that each has their own quality connected to the internet allows everyone to connect and exchange ideas between one and another other with just one touch. Also, the internet also provides a variety of facilities that allow each user to access various information such as exchange files, photos, videos and others (Anwar, Komariah, \& Rahman, 2017).

The development of technology in the modern era provides various facilities for all aspects of life. It could make it easy for people to meet their needs for food, clothing, and shelves and also help people to improve knowledge insights easily. However, society should not be lulled by it because the development of technology has two opposite sides. On the one hand, technological developments benefit humans, but on the other hand can be detrimental (Anwar, Rusmana, \& Rahman, 2018). If abused, the development of Internet technology can lead to social disease that quite critical in the midst of society.

However, technology also offers a new cure to such social diseases. Instagram, for example. Pittman and Reich (2016) suggest that loneliness may decrease, while happiness and satisfaction with life may increase, as a function of image-based social media use (Pittman \& Reich, 2016). In addition, Instagram users still see every post from the accounts they follow-unlike Facebook, which, by default, filters outposts it deems less interesting to the user (Salomon, 2013). The next significant finding was a positive relationship between those who scored high in interpersonal interaction and using Instagram for coolness, creative purposes, and surveillance (Sheldon \& Bryant, 2016).

However, in fact, technological developments not only support mobility in communicating. Technology also takes a role in a commercial aspect by the emergence of various online shopping sites. Nowadays, many manufacturers of goods and services are utilizing this technology as a means to market their products without having to open a physical store. The online shop is a means to offer goods and services over the internet so that online shop visitors can see the goods and services offered with very minimal effort. The online shop makes it easier shopping without having to spend much time and effort. So that its presence is highly demanded by all ages (Mary Wolfinbarger, 2001). The online shop allows the purchase of goods and services through internet media. Through online shopping, buyers can also see in advance the goods and services they want to get through the web promoted by the seller. Online shopping activities are a new form of communication that does not require face-to-face communication directly. Instead, it can be done separately from and to the whole world through the media of notebook, computer, or mobile phone, which is connected with internet 
access network service so that it is easier for everyone for doing the online transaction (Arthur Armstrong, 1999).

The process of buying and selling transactions in the online shop is done, by providing various conditions to prospective buyers. One of it is the requirement for prospective buyers to register as a member first. Buyers who are already becoming a member, then able to order the product. After that, customer pay for the products purchased by credit card or by bank transfer. The online shop owner then sends the product to the customer (Mary Wolfinbarger, 2001).

The first online shopping was occurring in the UK in 1979 by Michael Aldrich from Redifon Computers. Michael Aldrich hooked up a color television with a computer capable of processing realtime transactions via telephone cables. Since 1980, Michael Aldrich has sold online shopping systems across the UK (Arthur Armstrong, 1999).

Indonesia also went into this online shopping-fever. Now it is very easy to make purchases of various goods and internet services. From buying clothes, phone credit, book, ordering gifts, until done activities like paying credit cards, electricity bills, and phones, all is possible to be done just via the internet (Arthur Armstrong, 1999).

A survey conducted by UCWeb, a mobile browser maker in March 2016, found that $72.2 \%$ of people usually spend at least an hour for online shopping, and $87.4 \%$ of them shop through mobile devices. The first reason to shop online is the convenience of shopping wherever and whenever, then followed by seasonal or holiday promotions, followed by periodic necessities, such as buying for prizes in a short time for distant friends. It also found that most people shop online between $6 \mathrm{pm}$ and $10 \mathrm{pm}$.

The online shop has brought a new ambiance of culture and values in people's lifestyle. Almost most of the community, from teenagers, adults, until parents are also not a few found troubles with this advanced technology. This good welcoming can be seen from the number of people who use the online shop as a means of buying the desired goods. This is of course very good for economic growth in Indonesia. But behind it all, our society has started to enter in a condition where people always want to have something new that is currently trending, even the goods is not a need, but only as of the interest of prestige and only desire of lust.

Patterns of behavior like this should not be done because if online shopping becomes a habit, it will give bad impact on this nation. Society will be more consumptive in meeting all of its needs, especially teenagers. It's feared will kill the creativity of the next generation because technology has provided everything. This pattern of consumptive life proved that in everyday life, people always put high importance on the style of purchasing goods. People prefer good, fancy, trendy, and branded goods without thinking about the function and usefulness of the goods they buy. This is encouraged by the number of promotions or discount vouchers that are often offered by online shopping sites and also because people interested in cheap price goods, that make people more crowding in online shopping. Consumptive behavior can also lead to the nature and lifestyle of consumerism, namely nature or lifestyle that considers the goods as a measure of pleasure, happiness, and self-esteem. With style or nature like this, people will be recessive to buy goods and services that do not become their needs (Vitale, Noam, \& Tractinsky Michael, 2000).

The value of using is no longer important, the value of the social marks takes a great part. Now people have an understanding of the importance of joy and luxury in life without seeing any signs of religious prohibition and rules. Things like this are often seen in urban areas. Because in urban areas, all facilities can be obtained, so that people tend to live consumptively (Vitale et al., 2000). In the city, old learnings such as manners that given by our ancestors seemed to vanish due to this era of globalization. Globalization is unavoidable. Step by step the change takes place in society, for example, people start living consumptive lives.

Not a few of the students take advantage of existing technologies in the surroundings such as, smartphone and laptops that students have to do online shopping transactions. From that point, someone makes online shopping with the many numbers of advertisement promoted via Facebook, 
BBM, and Instagram. Research says that there is a positive relationship between high levels of social activity (traveling, going to sporting events, visiting friends, etc.) and being motivated to use Instagram as a means of documentation. As a result, there could be better to use Instagram than others in many deals, including businesses. In reference to narcissism, there was a positive relationship between using Instagram to be cool and for surveillance (Sheldon \& Bryant, 2016). That kind of narcissism could affect the purchasing power of the individuals.

It is then interesting to trace the responses of female college student of Islamic college, predicated as educated and religious people, towards Instagram social media and their relationship to their behavior. Here are the findings that can be presented here as a student experience of Islamic college.

\section{Research Method}

The method used in this research is a descriptive method that is given, describing, illustrating, and explaining the phenomenon of the research object, which is college student life with social media Instagram. This method explains the object data naturally, objectively and factual (Silverman, 2015). The way is to collect and analyze data that is related to the object of study.

This research takes a qualitative method because it is on a scientific background, using natural methods, and done by researchers who are interested in a natural way. This research is intended to understand the phenomenon of what is experienced by research subjects, such as behavior, perception, motivation, action, holistic, and with a special context that is natural and by utilizing various scientific methods (Mayan, 2016).

Because the research is intended to describe the ongoing issues. Therefore, this method fits perfectly with the research problem. Data collection began with collecting data in the field, then analyzing it and ending it by giving a conclusion to the problem above, and finally all of those compiled into a research report.

\section{Result and Discussion}

The development of information technology today is constantly providing convenience for the public in obtaining information needs. One of the information communication technology that is increasingly used today is social media Instagram.

Instagram is one of the many social media that people have the interest of. This application that created by Kevin Systron can attract the attention of users of various ages (Scholl, 2015). Not only teenagers who use this application, but also children, parents until state officials also use Instagram.

The main feature of Instagram is sharing photos and videos with fellow users. Even before uploading a photo or video, the user may edit it by giving a filter. At the beginning of its emergence, Instagram is intended for users of smartphones, but now it's also accessible through the desktop. In the original plan, any user who uploaded a photo can get comments and likes from other users (Scholl, 2015).

Also, any photos or videos uploaded to Instagram can also be connected with Facebook, Twitter, and Foursquare. Also, of uploading personal photos, the user can also see other things like photos of fashion clothing that is currently trending (Scholl, 2015).

In this modern era, most people have the feeling of being out of date and inferior when not buying and owning the latest product perceived as part of the identity of the community's status. The existence of an Instagram phenomenon that developed in the community, especially teenagers, is now part of the development of new media. The development of this new media cannot be avoided, because it is included in the development of human life (Hayumi, 2014).

Among female students, Instagram is now one of the must-have applications. It can be seen that the community affected by the use of Instagram makes a change in human behavior will awareness itself, to display the things that he documented in the form of photos and video. "Most of 
the students, when looking for fashion models, they find it on Instagram or ootd (outfit of the day) of up to date artists" (Interview with YL, 18/6/2018).

In addition to its trendy, there is also an entertaining phenomenon. Admitted that if already open Instagram application, it will be felt fun. "Because in social media Instagram a lot of latest info that is presented very entertaining" (Interview with MN, 18/6/2018). In addition to info, there is also reference style of dress, "Instagram somewhat one of the social media that make the user feel comfortable" (Interview with MT, 18/5/2018). Not just fashion or food. The news is also presented. So, it's very easy for getting every information that wanted to be known (Interview with MR, $18 / 5 / 2018)$.

In the phenomenon of outfit style, more teenagers explore themselves. They tried various fashion styles to then wait for the response from their surroundings (Entwistle, 2015). The strong encouragement from teenagers that they deserve attention from the surroundings is an indication that it is necessary to balance the need for attention to the need to understand environmental expectations.

The study of fashion is not only about clothing, but also about the role and meaning of clothing in social action. In other words, fashion can be referred to as the social skin in which it brings the message and lifestyle of a particular community that is part of social life (Malcolm Barnard, 2013). Also, fashion also expresses a certain identity. Clothing is one of the most distinctive marking ranges of external appearance, with which one is distinguished from the others, evolving towards the identity of a particular group (Niinimäki, 2010). This is also reinforced by the opinion of Solomon (Solomon, Russell-Bennett, \& Previte, 2012) that "clothing according to products of known products can reflect the social life of the consumer, fantasy and fashion membership is a category."

It is undeniable that the world of fashion is experiencing a very rapid development along with the times. Fashion has become a topic of daily conversation. Being fashionable seems to have become a necessity for some people. Fashion has become a necessity because fashion is way more than only clothes, but it can be a way of expressing oneself (Interview LL, female, 7/5/2018).

Students stated more firmly that the style of clothing is undergoing rapid development because it cannot be denied because of the many factors that cause the style of clothing to increase due to the technology and information flow that makes Indonesians open to follow current fashion trends. For example, such as advertising on social networks and television that presents several models of contemporary fashion. Thus, those make people interested and want to have the clothes as celebrities wear them (Interview AG, 5/7/2018).

Another student adds that the development of fashion today is increasingly diverse, but older models are repeated and used again, so the cycle is continuous. Unconsciously we use the style of old fashion, for example, cutbray pants that are currently trending again (Interview MM, 5/18/2018).

Fashion is understood as something individual because, with fashion, a person can show their personality. Although its individualized, with social media such as Instagram, people can freely imitate celebrity fashion styles and even spend money voluntarily to buy clothes with an aim to be looked trendy. But in reality, fashion also depends on the comfort, but certainly, of the community, especially of the students who notice freedom of expression, among them, they competing to follow the latest fashion style (Interview SF, 5/15/2018).

Indeed, "social media can provide our daily access to clothing by mixing and combining the clothes we want... so I do not wonder if there is a style of dress that is imitating celebgram" (Interview ML, 5/20/2018). Social media is a place where many notices about the style of the current trending style, either by consciously or unconsciously, it indirectly affects the style of dress at this time because it looks attractive, not too complicated and simple. The transition from looking into buying also occurs because of social media. Here, the student also makes a purchase through the online store, "very easy for students to find the clothes we want because we do not have to go out from the house" (Interview MF, 5/13/2018).

Female college students like to buy because it is driven by the basic nature of women who like to shop, especially if women are seen eye-catching clothes. It makes female college students want 
to have it, so most of them, collecting clothes is essential. Especially with the development of technology that makes everything is easier for people, so without having to go out of the house and look for the desired clothes, people can look at fashion models that are currently trending on Instagram and people can even get the desired fashion by buying online. It is surprising that almost all of 30 percent of their pocket money they spent to whatever they saw in Instagram. Shortly after that, they shop on the online shop.

The use of an online shop for students is a lifestyle change that initially had to jostle in the market and interacting directly with sellers has now become a new and practical thing without having to feel things like that. These changes provide a change in value, namely the social value that originally shopped all kinds of needs in the market using direct communication, but otherwise, in an online shop such things cannot be found. Enough with a smartphone connected to the internet network the buying and selling process can be done without any process of bargaining with each other or communicating directly with the seller.

Students are users of internet facilities that access technology almost every day. The phenomenon of online shopping has become something new that has more or less an impact on student consumption patterns. But this does not affect curiosity about online shops.

This was reinforced by the statement of a student of class 2015: "Before getting to know the online shop I bought necessities at traditional markets, clothes shops or at the mall. But now I shop more frequently at online shops because I keep up with the times and it's easier though I'm not mistaken. I also buy it at the store for those who don't have time or are shy about going to an alternative shop, yes online shop" (Interview FZ, 5/13/2018).

FZ's statement proves that there is a shift in shopping patterns that started shopping at traditional markets, clothing stores and malls after getting to know the online shop. FZ is more interested in shopping through online shop services. The same statement was also explained by $\mathrm{SH}$ according to him: "After the online shop we do not need to bother going somewhere to look for items that we want to buy. Through an online shop we can order the items we need. Before getting to know an online shop I usually buy my needs at malls, markets and certain shops" (Interview SH, 5/13/2018).

Students now to get the goods want always easy and practical, without the hassle of going out of the house or boarding house to find something. So that the online shop is very helpful for students to meet all their needs. Be it books, clothes, watch bags and more, all in the online shop.

Online shop services indirectly affect the consumption patterns of students who initially consume goods as a need, but change their function or switch to patterns to show their self-identity around their environment. Things like this have an impact on the lifestyle of students who initially did not place much importance on appearance, but after having been involved in the online shop world students tend to be more concerned with appearance to show a better self-image in the community.

This was also strengthened from the results of the interview with informant brother NA according to him: "There are distinct differences between students who are involved in online shops and those who are not. In my opinion, students who use online shop services in terms of appearance or fashion are different. So it seems that people who use online shop services are students who have money" (Interview FZ, 5/13/2018). The statements of several informants who wrote the interview were not much different from what was stated by brother NA. SH also stated that: "Obviously the difference between students who do not use online shops and those who use online shop services. Usually, students who use an online shop are more fashionable trendier than people who have never used an online shop in my opinion like that one of them" (Interview SH, 5/13/2018).

Students choose to buy online so that they are not technology illiterate depending on the perception of the students themselves. Students will feel more comfortable if said as part of modern humans. One of them is by using an online shop as an alternative in shopping. So, students are not said to be people who lack understanding about the technology that is now developing rapidly. One of the informants interviewed by the author revealed that: "Students who have used an online shop tend to follow the modern style now. Different who have not used the online shop have not followed 
the way of shopping in the current era or not yet present" (Interview FZ, 5/13/2018).

However, the existence of an online shop makes students consumptive. According to DN, a semester 8th student of biology education major said there was a fundamental difference between excessive online shop users and non-users. DN said that: "Realistic difference in mindset in managing funds used in spending" (Interview DN, 5/13/2018).

Students who frequently shop through online shops tend to be less good at managing spending money compared to students who only shop when they really need it. They just simply obey their wishes without considering that the goods they buy are needed or not. Brother WW, who has been managing Universal boarding school stores for more than 5 years, said: "Since I started working here, so many changes are happening now. One year ago, there were not many students who shop online. Only one, two only in one month. But now almost every day I receive packages on behalf of Universal students" (Interview WW, 5/13/2018).

Besides actively shopping at online shops, students also use the online shops to get additional benefits. With an online shop makes it easy to sell goods without having to bother offering merchandise. Enough with a smartphone someone can market their merchandise. This was stated by AG as follows: "Not only as a consumer, I also sell in several well-known online shop applications in Indonesia such as clothes handphone accessories and others" (Interview AG, 6/13/2018). KJ added that: "With the online shop we are given its own advantages. We know that each student has their own activities and activities, with an online shop when there is no time to go out looking for items that we want to order, we just need to open social media like Instagram, Facebook, Twitter, and many online shop applications. Popping up like Tokopedia, Bukalapak, and Shopee"(Interview KJ, $6 / 13 / 2018)$.

The development of fashion trend in Indonesia is driven by several factors, such as social media, the entertainment world, business world, and the internet (Castells, 2009). The celebrities who always appear in various media and become an idol, always changing fashion style, either following the fashion trends or sponsorship. This could be the cause of society to follow. It has become a law of nature, if the idol is a trendsetter, will be followed by the people who become their fans. As a developing party who is looking for a model of life, female college students would certainly follow a style that they think relate to them, which is the celebrities who appear in Instagram, or also called as celebgram.

With the existence of an idol to be followed and supported by the capability to get the clothes they want - for example, just get pocket money from parents, of course, female college students more focus for online shopping. Here they are transforming from Instagram readers to those who jump into Instagram. From Instagram, they see the model. They want to be like the model. When they about going to college, even they are the models themselves. And they also uploaded it back to Instagram.

Seeing the description above, the student has been practicing the S-O-R Theory (Stimulus Organism - Response) that originally derived from psychology. As said before, that the fashion issue is a personal matter, then it is also psychological. Then it can also be a communication theory because the material objects of psychology and science of communication are the same, that is, the human soul includes components: attitudes, opinions, behaviors, cognitions, affections, and conations (Charms, 2013).

According to Stimulus Theory of Response, the effect is a special reaction to a special stimulus, so that one can expect and predict the suitability between the message and the reaction of the communicant. So, the elements in this model are a message (stimulus), communicant (organism), and the effect (response) (Heath \& Bryant, 2013).

In the communication process about attitude change are aspects of "how" not "what" and "why." To be clear how to communicate regarding with this, how to change the attitude, how to change attitudes communicant. In the process of changing attitudes, it appears that attitudes can change only if the stimulus that strikes exceeds the original. Hovland, Janis, and Kelley (Richard E Petty, 2018) state that in examining the new attitude there are three important variables: attention, 
understanding, and acceptance.

Stimulus or message conveyed to the communicant may be accepted or may be rejected. Communication will take place if there is attention from the communicant. The next process is a communicant who understands. This ability of the communicant continues the next process. After the communications sort it out and accept it, then there is a willingness to change attitudes (Watzlawick, Bavelas, \& Jackson, 2011). Then, behavior change is based on Stimulus-Organism-Response.

Behavior changes occur by increasing or multiplying stimulus. Therefore, behavioral changes occur through the learning process. A natural change is a behavioral change due to natural changes (environment) naturally. There are also planned changes, which is when the behavior changes because it is planned. The changing demands a changed attitude of change, i.e., behavioral change due to the internal process of the self, in which the internal process is different for each (Daniel T. Holt, Achilles A. Armenakis, Hubert S. Feild, 2007).

After all, for Muslim college students, Muslim clothing is simple, and there is harmony between tops and pants / skirts that looked beautiful, pleasant and polite because it follows the rules of shari'a. But even in the clothing, Muslim, Instagram has a story that is stimulating and demands a different response.

\section{Conclusion}

Based on the description above, it can be concluded that: 1) social media Instagram become a phenomenon among female college students because the Instagram is one application that is currently very booming among them because the users are always being spoiled by the various features that Instagram provide. Moreover, there are thought that if you do not have an Instagram account, they will be considered outdated. With Instagram, the fashion world is growing rapidly and more varied. With the Instagram application, a female college student can easily find the reference of latest trending styles; 2) female college students get many internet support, for example, now that in campus there is large bandwidth provided so that the student can launch social media like Instagram easier. Internet procurement also occurred in the boarding-lodging where the female college students live, so the students are really addicted and cannot be separated from the life of the internet, especially social media; and 3) the impact of widespread access to the internet has made many female colleges of students do the reading and online transactions in terms of fashion, so that they become more consumptive than they did through face to face trading.

\section{References}

Anwar, R. K., Komariah, N., \& Rahman, M. T. (2017). Pengembangan Konsep Literasi Informasi Santri: Kajian di Pesantren Arafah Cililin Bandung Barat. Wawasan: Jurnal Ilmiah Agama Dan Sosial Budaya. https://doi.org/10.15575/jw.v2i1.964

Anwar, R. K., Rusmana, A., \& Rahman, M. T. (2018). The Politics Of Information On Traditional Medical Practices In Bandung Barat. MIMBAR, Jurnal Sosial Dan Pembangunan, 34(1), 158-165. https://doi.org/https://doi.org/10.29313/mimbar.vol34iss1pp\%25p

Arthur Armstrong, J. H. I. (1999). The Real Value of On-Line Communities. In Creating value in the network economy. Harvard Business Review Press.

Castells, M. (2009). Communication Power. Oxford, Ney York: Oxford University Press.

Charms, R. de. (2013). Personal Causation: The Internal Affective Determinants of Behavior. New York, London: Routledge.

Daniel T. Holt, Achilles A. Armenakis, Hubert S. Feild, and S. G. H. (2007). Readiness for Organizational Change: The Systematic Development of a Scale. The Journal of Applied Behavioral Science, 43(2), 232-255. https://doi.org/https://doi.org/10.1177/0021886306295295

Entwistle, J. (2015). The Fashioned Body: Fashion, Dress and Social Theory. John Wiley \& Sons Inc. 
Gubbi, J., Buyyab, R., Marusica, S., \& Palaniswamia, M. (2013). Internet of Things (IoT): A vision, architectural elements, and future directions. Future Generation Computer Systems, 29(7), 1645-1660. https://doi.org/https://doi.org/10.1016/j.future.2013.01.010

Hayumi, N. Z. (2014). Penggunaan Instagram sebagai Bentuk Eksistensi Diri.

Heath, R. L., \& Bryant, J. (2013). Human Communication Theory and Research: Concepts, Contexts, and Challenges. New York, London: Routledge.

Indermun, V. (2014). IMPORTANCE OF HUMAN RESOURCE MANAGEMENT PRACTICES AND THE IMPACT COMPANIES FACE IN RELATION TO COMPETITIVE CHALLENGES. Singaporean Journal of Business Economics, and Management Studies, 2(11), 125-135. Retrieved from https://www.singaporeanjbem.com/pdfs/SG_VOL_2_(11)/9.pdf

Malcolm Barnard. (2013). Fashion as Communication. New York: Routledge.

Mary Wolfinbarger, M. C. G. (2001). Shopping Online for Freedom, Control, and Fun. California Management Review, 43(2), 34-55. Retrieved from http://journals.sagepub.com/doi/pdf/10.2307/41166074

Mayan, M. J. (2016). Essentials of Qualitative Inquiry. New York: Routledge.

Niinimäki, K. (2010). Eco-clothing, consumer identity and ideology. Special Issue: Sustainability and Identity, 18(3), 150-162. https://doi.org/https://doi.org/10.1002/sd.455

Pittman, M., \& Reich, B. (2016). Social media and loneliness: Why an Instagram picture may be worth more than a thousand Twitter words. Computers in Human Behavior, 62, 155-167. https://doi.org/10.1016/j.chb.2016.03.084

Richard E Petty, J. T. C. (2018). Attitudes And Persuasion: Classic And Contemporary Approaches. New York: Routledge.

Salomon, D. (2013). Moving on from Facebook: Using Instagram to Connect with Undergraduates and Engage in Teaching and Learning. College and Research Libraries News, 74, 408-412. https://doi.org/10.5860/crln.74.8.8991

Scholl, H. (2015). Instant Profits Guide to Instagram Success. Hillary Scholl.

Sheldon, P., \& Bryant, K. (2016). Instagram: Motives for its use and relationship to narcissism and contextual age. Computers in Human Behavior, 58, 89-97. https://doi.org/10.1016/j.chb.2015.12.059

Silverman, D. (2015). Interpreting Qualitative Data. Los Angeles, London, New Delhi, Singapore, Washington DC: Sage Publications.

Solomon, M., Russell-Bennett, R., \& Previte, J. (2012). Consumer Behaviour. Australia: Pearson Australia.

Vitale, S. L., Noam, J., \& Tractinsky Michael. (2000). Consumer trust in an Internet store. Information Technology and Management, 1(1-2), 45-71.

Watzlawick, P., Bavelas, J. B., \& Jackson, D. D. (2011). Pragmatics of Human Communication: A Study of Interactional Patterns, Pathologies and Paradoxes. New York, London: WW Norton \& Company. 
Name of Writers | Article's Title

To cite this document:

Anwar, R. K., et. al. (2020). The Impact of Using Instagram Social Media on Student Consumptive Behavior. Record and Library Journal, 6(1), 80-88.

Open access under Creative Commons Attribution-Share A like 4.0 International Licence

(CC BY-SA) @ (1) (2) 